Rev Biomed 2001; 12:288-289.

\title{
Deceso de venado cola blanca (Odocoileus virginianus) por mordedura de serpiente: reporte de caso.
}

Armando Rubio-Delgado, Fabio G. Cupul-Magaña.

Departamento de Ciencias, Centro Universitario de la Costa, Universidad de Guadalajara, Puerto Vallarta, Jalisco, México.

Se documenta la muerte de un venado cola blanca, hembra de dos años de edad y $30 \mathrm{~kg}$ de peso, mantenida en cautiverio en las estalaciones de un centro vacacional localizado a $20 \mathrm{~km}$ al norte de Puerto Vallarta, Jalisco. El ejemplar fue trasladado, junto con otros tres venados a sus nuevas instalaciones, dentro del mismo centro, sin ningún tipo de contratiempo. Al cuarto día de su traslado, en el ejemplar se detectó anorexia, deshidratación severa y claudicación en miembro anterior izquierdo. Un día después, para practicarle manejo, se sedó con Ketamina 2 mg/kg y Xilacina $2 \mathrm{mg} / \mathrm{kg}$. Al revisar la cara interior del miembro delantero izquierdo (a la altura del codo), se observaron laceraciones cutáneas, dos heridas circulares con necrosis periférica y separadas 0.5 $\mathrm{cm}$ una de la otra. Todo el miembro se encontraba edematizado e hipotérmico con dermatografismo, además de la presencia de líquido de infiltración y hemorragia subcutánea. En general, el ejemplar presentaba hipertermia, cianosis en mucosas, distensión abdominal marcada y atrofia muscular. Para atacar esta situación, se le aplicó Amikacina como antibiótico y Piroxicam como desinflamatorio. Ese mismo día de manejo, a las 22:35 h, el ejemplar falleció.

La necropsia reveló hemorragia subcutánea y mionecrosis en el tríceps. Todos los demás tejidos fueron aparentemente normales. Por otra parte, los pulmones se encontraron difusamente hemorrágicos; hemorragias en mesenterio; enterolito $(550 \mathrm{~g})$ en colon menor, distendido y mucosa con halo rojo-negruzco y ulceraciones en contacto con enterolito. Asimismo, el tejido muscular y piel presentó daño severo local, edema, hemorragia y mionecrosis; además, en el tejido se encontró una cantidad considerable de proteínas de alto peso molecular ocasionando lisis celular. En el riñón se observaron hemorragias petequiales. La muestra de tejido cardíaco (pericardio) se encontró totalmente hemorrágico. En las muestras de sangre y líquido de infiltración, se encontró lisis

Solicitud de sobretiros: M. en C. Fabio G. Cupul-Magaña. Depto. de Ciencias, Centro Universitario de la Costa, Universidad de Guadalajara, Av. Universidad de Guadalajara No. 203, Delegación Ixtapa, C.P. 48280, Puerto Vallarta, Jalisco, México. 


\section{A Rubio-Delgado, FG Cupul-Magaña.}

celular y restos considerables de proteínas de alto peso molecular.

Las observaciones realizadas permiten diagnosticar intoxicación por mordedura de serpiente, aunque el ejemplar nunca fue encontrado. Las referencias locales, remiten a dos posibles especies: la serpiente cascabel del Pacífico (Crotalus basiliscus) y el zolcuate o cantil (Agkistrodon bilineatus) (1), mismas que presentan veneno de tipo proteolítico. Cabe mencionar, que por el tamaño de la herida, se puede suponer que el agresor del venado cola blanca fue un zolcuate. A continuación se describen algunos aspectos importantes de ambas especies. La serpiente cascabel de la costa (Crotalus basiliscus), es un ejemplar grande (hasta $2.6 \mathrm{~m}$ de longitud) que presenta una coloración café verdoso claro, con rombos oscuros de centros y márgenes claros en el dorso del cuerpo; además de su característico cascabel al final del cuerpo. Es de vida nocturna y se alimenta, en su mayoría, de roedores. La zolcuate, gamarrilla o cantil (Agkistrodon bilineatus), es una serpiente pequeña (hasta $75 \mathrm{~cm}$ de longitud), que presenta una coloración negra a marrón con puntos blancos amarillentos que tienden a formar líneas verticales. La cabeza presenta dos líneas claras a cada lado desde la punta de la cabeza hasta la nuca, una pasa por arriba del ojo y otra sobre el labio superior, siendo las juveniles más claras que las adultas y la cola es siempre de color amarillo limón. Son nocturnas y terrestres. Se alimentan de roedores, lagartijas, ranas y peces que los atrae moviendo la cola como si fuera un gusano (2).

Para la Bahía de Banderas, se registraron en el año 2000 ocho casos de mordedura de serpientes en humanos, siendo la cascabel la principal protagonista. Sólo en un caso, ocurrió el deceso de una niña de 18 meses de edad.

Palabras clave: Venado cola blanca, envenenamiento ofídico, crotalus, Agkistrodon.

\section{REFERENCIAS.}

1.- Cupul-Magaña FG. Animales silvestres venenosos de Bahía de Banderas, México. Rev Biomed 1998; 9:124-5.

2.- García A, Cevallos G. Guía de campo de los reptiles y anfibios de la costa de Jalisco, México. México: Fundación Ecológica de Cuixmala, A. C. Instituto de Biología, UNAM; 1994. p. 184.

\section{Revista Biomédica}

